\title{
Patient Satisfaction with Regard to Ophthalmic Ultrasound Services Offered at King Khaled Eye Specialist Hospital, Riyadh City, Saudi Arabia: A Cross-Sectional Study
}

\section{Thafer S Bedaiwi ${ }^{1,2 *}$, Ahmed A AlKhalifa ${ }^{2}$, Rajiv Khandekar ${ }^{3}$ and Saleh A AlKhaldi ${ }^{4}$}

${ }^{1}$ Department of Digital Imaging, King Khaled Eye Specialist Hospital, Riyadh, Saudi

Arabia

${ }^{2}$ College of Health Sciences, Saudi Electronic University, Riyadh, Saudi Arabia

${ }^{3}$ Research Department, King Khaled Eye Specialist Hospital, Riyadh, Saudi Arabia

${ }^{4}$ Department of Ophthalmology, King Saud Medical City, Riyadh, Saudi Arabia

*Corresponding Author: Thafer S Bedaiwi, Department of Digital Imaging, King

Khaled Eye Specialist Hospital, Riyadh, Saudi Arabia.
Received: March 29, 2021

Published: April 21, 2021

(C) All rights are reserved by Thafer $\mathbf{S}$

Al-Badawi., et al.

\begin{abstract}
Aim: To review patient satisfaction of ultrasound services at a tertiary eye care center.

Methods: This cross sectional study was performed in 2019. A survey was performed in Arabic, that queried patient demographics, staff interaction, ease of access, patient satisfaction, and quality of the techniques. Responses were graded on a 5-point Likert scale. The logit score for satisfaction was correlated to demographics and other variables was statistically significant ( $\mathrm{p}<0.05)$.

Results: Three hundred and sixty-six patients were interviewed. The median patient satisfaction logit score was -13.0 [Interquartile range (IQR) -16.1, -8.3; Minimum -29.6, Maximum-8.3]. There were 333 (91\%) patients who reported positive satisfaction and $33(9 \%)$ reported very positive satisfaction. Patient satisfaction did not differ based on gender (Mann Whitney p = 0.77). Age was statistically significantly correlated to patient satisfaction (Pearson $\mathrm{p}=0.038$ ). The median score of a subgroup of satisfaction for 'Interaction and Communication' (-5.1) was statistically better than 'Technical Quality of Services Offered' (0.4) and general issues of service (0.2). ( $\mathrm{p}<0.001)$. However, it was not significantly different from satisfaction with accessibility of services $(-3.3)$.

Conclusion: The high level of patient satisfaction for the ultrasound services provided at a tertiary eye hospital is encouraging. The factors affecting patient satisfaction could be further improved to ensure greater enhancement of ancillary services for ophthalmic patients.
\end{abstract}

Keywords: Client Satisfaction; Ultrasonography Services; Comprehensive Eye Care

\section{Introduction}

In any service oriented industry, clients are important stakeholders [1]. This includes private or public (government subsidized) healthcare services where the goal is improving quality to satisfy the end users [2]. Patient satisfaction is an individual's cognitive evaluation of, and emotional reaction to, his or her healthcare experience [3]. Hence, patient satisfaction is a recommended tool for assessing the quality of different healthcare sectors $[4,5]$. Notably, this tool is not related to the quality of surgical care or accreditation status of the hospital [6,7] in Iran [8], patient satisfaction 
was evaluated and outcomes were used to improve the quality of eyecare services. In ophthalmic services, waiting time is the most important factor for consultations [9]. There is a plethora of literature on patient satisfaction for different eye surgeries. However, studies of satisfaction with ancillary ophthalmic services offered at an eye hospital are rare.

A tertiary eyecare hospital delivers diagnostic and surgical care yet, there are a number of ancillary services for patients including laboratory diagnostics, digital imaging, radiology, ultrasound and health education. It is important to understand the patient experience with these ancillary services in order to propose policy changes that improve the quality of these services. Patients with cataract, vitreoretinal diseases and orbital pathology are routinely referred to the ultrasonography unit to assist ophthalmologists in diagnosis and management.

King Khaled Eye Specialist Hospital in Riyadh is a state of art eye hospital catering to population of Saudi Arabia since 1983 [10]. It has integrated its mission to the VISION 2030 initiative for Saudi Arabia [11]. Improving all aspects of quality of care can satisfy existing patients and make them agents for promoting health tourism; a future goal of the hospital.

To the best of our knowledge, there are no studies that surveyed patients on their satisfaction with ancillary ophthalmic services. In the current study, we evaluate patient satisfaction with an ophthalmic ultrasound service and its determinants at a tertiary eye hospital in central Saudi Arabia.

\section{Methods}

The study was approved by the Institutional Research Board (2039-P). This study adhered to the tenets of the declaration of Helsinki. Written informed consent was obtained from each participant. Patients were included if they were 18 years and older and presenting to the ophthalmic ultrasound department between April 1 and April 30, 2020. Patients who were critically ill or those who were examined while unconscious were excluded from the study. Those declining to participate in the study were also excluded. All patients awaiting their exam for ophthalmic ultrasound were approached for participation and were advised that non-participation would not affect their care and management.
Annually, up to 40,000 patients utilize the ophthalmic ultrasound service at this institute. We assumed that $72 \%$ of these patients were highly satisfied with the service [12]. To achieve 95\% confidence interval (CI) and 5\% acceptable error margin with a clustering effect of 1.2, 370 patients were required. Open Epi software was used to calculate the sample size [13].

One ultrasonographer and one radiology technician were the field investigators.

Data were collected on patient demographics. A previously validated Patient Satisfaction Questionnaire-18 (PSQ-18) was used to survey the patients [14]. Of the 18 questions, 2 questions were omitted to make it suitable for the study site. Since all services are free of cost satisfaction with cost was omitted. All precautions were taken to prevent the potential spread of SARS-COV2 during the Covid 19 pandemic. The questionnaires was translated to Arabic and validated by reverse translation. If a patient was illiterate, his caretaker or the field investigator assisted in explaining the questions. of the sixteen questions related to satisfaction, two were related to satisfaction in general, with the services, four questions were related to Interaction and Communication, four questions were about Technical quality of the services offered and six were related to accessibility of ultrasonography facilities.

The responses were graded on a 5-point Likert scale [15]. The participant was allowed to not respond to a question if he/she did not want to. Those with a positive satisfaction response had logit scores of -1.1 and -2.63 . Those with a negative satisfaction response had logit scores of 0.09 and 2.83. Neutral responses were scored as zero. The sum of all responses for each patient was calculated as the 'overall satisfaction score'. A negative satisfaction score denoted positive satisfaction. To compare subgroups, the sum of satisfaction logit score was divided by the number of questions in each subgroup.

The data were collected in an Excel spreadsheet (Microsoft Corp., Redmond, WA, USA). The main outcome of the study was the sum of the logit scores for the 16 satisfaction related questions. The data were then transferred to Statistical Package for Social Studies (SPSS version 26) (IBM Corp., Armonk, NY, USA). The total score was plotted to study the distribution. If the distribution was normal, the mean and standard deviation are reported. If the data distribution was non-normal, the median and interquartile range 
(IQR) are reported with the minimum and maximum values of the score. The subgroup satisfaction scores were also calculated. The score was correlated to gender and age. Validation was performed using a nonparametric method. The Mann-Whitney $\mathrm{P}$ value was calculated to compare scores by gender. $\mathrm{P}<0.05$ was considered statistically significant.

\section{Results}

A total of 366 patients comprised the study sample. The mean age of the study sample was $49.7 \pm 16.2$ years. There were 212 (57.9\%) males and 154 (42.6\%) females.

The median logit score of patient satisfaction was -13.0 (IQR -16.1; -8.3) [Minimum -29.6; maximum-8.3]. Three and thirty three (91\%) patients reported positive satisfaction patients and 33 (9\%) patients reported very positive satisfaction.

The logit score was -13.0 (IQR -16.0; -8.5) among males and -13.0 (IQR - 17.2; -8.1) among females. Patient satisfaction was not significantly different between genders (Mann Whitney $\mathrm{P}=0.77$ ).

Age was statistically significantly correlated to patient satisfaction (Pearson $\mathrm{P}=0.038$ ). The logit score in four subgroups of satisfaction is compared in figure 1 and table 1 . Interaction and communication and accessibility components of the ophthalmic ultrasound service were positive. The variation of scores in subgroup was statistically significant (Friedman $\mathrm{P}<0.001$ ).

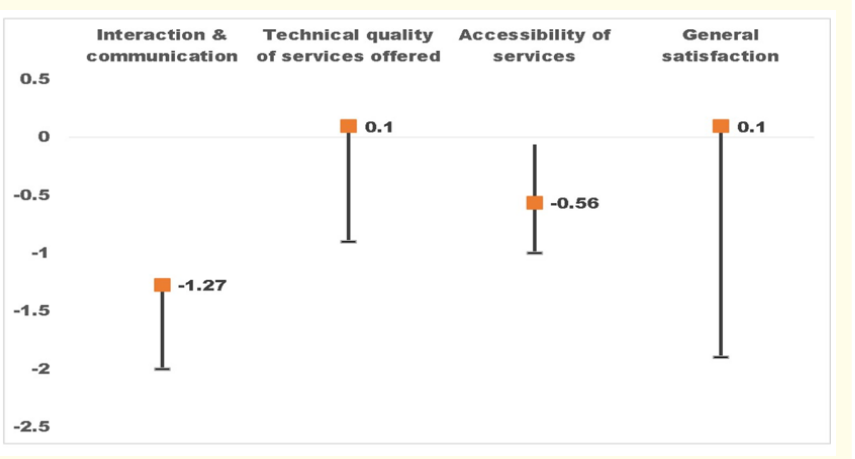

Figure 1: Demonstrates the satisfaction for ultra-sonography services by subgroup of satisfaction.

\begin{tabular}{|l|c|c|c|c|c|}
\hline \multicolumn{1}{|c|}{ Logit score } & Median & IQR & Minimum & Maximum & Validation \\
\hline $\begin{array}{l}\text { Interaction and } \\
\text { communication }\end{array}$ & -5.1 & $-7.9 ;-5.1$ & -10.5 & 0.72 & \\
\cline { 1 - 5 } $\begin{array}{l}\text { Technical } \\
\text { quality of } \\
\text { services } \\
\text { offered }\end{array}$ & 0.4 & $-3.5 ; 0.4$ & -7.8 & 5.9 & \multirow{2}{*}{$\mathrm{p}<0.001$} \\
\cline { 1 - 4 } $\begin{array}{l}\text { Accessibility of } \\
\text { services }\end{array}$ & -3.3 & $\begin{array}{l}-6.1 ; \\
-0.36\end{array}$ & -14.2 & 6.1 & \\
\cline { 1 - 4 } $\begin{array}{l}\text { General } \\
\text { satisfaction }\end{array}$ & 0.2 & $-3.7 ; 0.2$ & -5.3 & 2.8 & \\
\hline
\end{tabular}

Table 1: Shows the satisfaction for ultra-sonography services by subgroup of satisfaction.

\section{Discussion}

Nine out of ten eye patients and their relatives were satisfied with the ophthalmic ultrasound service at the institute. Satisfaction improved with increasing patient age. Both male and female patients had similar satisfaction. Interaction and communication of the ultrasound staff and accessibility of services were positive for satisfaction compared to technical quality of the services.

To our knowledge, this is the first study from an eye hospital that evaluates patient satisfaction with ancillary services utilized by adult eye patients and their relatives. Patients base their overall satisfaction on their interaction with ophthalmic professionals (e.g. ophthalmologists, technologists, technicians and nurses), management outcomes and on their experiences with ancillary services such as ultrasound. The outcomes of the present study could be used as baseline data for future studies. Additionally, the data from this study could impact strategies to further improve the ophthalmic ultrasound services in the future. Similar studies should be performed in other services such as laboratory, anesthesia, health promotion, security, administrative and low vision services.

In the present study the patient satisfaction level for the ophthalmic ultrasound service was $91 \%$. A previous study of patient satisfaction with obstetric ultrasound reported more than $50 \%$ of patients at a government hospital were satisfied with all service components except the waiting period [15]. An Indian study conducted at a government hospital found that $90 \%$ of patients reported concerns over overcrowding in the sonography unit that resulted 
in issues of confidentiality and discomfort [16]. In the current study the well-organized infrastructure at the hospital resulted in an appropriate volume of patients in the waiting room (i.e. no overcrowding) and hence, no dissatisfaction.

In ophthalmology, ultrasonography is a fundamental imaging modality for diagnosis, management and monitoring of disease progression with and without intervention [17]. Ophthalmic ultrasound is especially useful in cases with opaque media that precludes funduscopy or other imaging modalities for evaluating pathology [18]. Cataract surgery is the most commonly performed ocular surgery and requires an accurate measurement of axial length using A-scan ultrasound in order to calculate the appropriate intraocular lens power [19]. Color Doppler a type of ultrasound investigation is useful to study ocular and orbital vascular pathologies [20]. Most patients under investigation or treatment for blinding eye diseases require ultrasound imaging. Therefore, a good patient experience and a good recollection of the visit to the ophthalmic ultrasound is crucial as patient word of mouth is an important factor in generating new patient visits.

In the present study, patient satisfaction did not vary by gender. This was also noted in another study of primary health care services in Saudi Arabia [21]. Equal access and free health care services likely explains the similar satisfaction between genders.

Older age was correlated to higher patient satisfaction in the current study. Sodani., et al. [16] also reported similar findings. Younger patients seem to be more impatient is likely the reason for dissatisfaction with the waiting period for and ophthalmic ultrasound.

In the present study, four components of patient satisfaction were reviewed. Of these, staff interaction with patients and communication about the procedure was satisfying to the patients. The waiting time resulted in some patient dissatisfaction. Different components and the determinants of patient satisfaction in a primary health care setting in Saudi Arabia have been well described by Mohamed., et al [22].

There some limitations in our study including the fact that the indication for ophthalmic ultrasound was not recorded. This could have further improve the strategy to focus on weaker areas of the service. Healthcare administrators of the hospital can evaluate at the factors leading to patient dissatisfaction in the present study and address these to further enhance patient satisfaction with sonography investigations. Similar studies should be performed by other ancillary departments at major hospitals for internal comparison of services and satisfaction as well as to establish healthy competition among service providers.

\section{Conclusion}

In this study, we used both descriptive methods and quantification by logit score of patient satisfaction with the ultrasound service. The high level of patient satisfaction is promising. Although staff-patient interaction and communication generated positive satisfaction, the long waiting periods need to addressed by revising scheduling, expanded hours, increasing the number of sonographers and sonography devices. The data from this study could be used to further improve ancillary service delivery to ophthalmic patients.

\section{Conflict of Interest}

None.

\section{Funding}

None.

\section{Bibliography}

1. Srivastava K and Sharma NK. "Service quality, corporate brand image, and switching behavior: The mediating role of customer satisfaction and repurchase intention". Services Marketing Quarterly 34.4 (2013): 274-291.

2. Chang CS., et al. "Service quality, trust, and patient satisfaction in interpersonal-based medical service encounters". BMC Health Services Research 13.1 (2013): 22.

3. Shirley ED and Sanders JO. "Patient satisfaction: implications and predictors of success". Journal of Bone and Joint Surgery 95.10 (2013): e69.

4. Mboya D., et al. "Embedding systematic quality assessments in supportive supervision at primary healthcare level: application of an electronic Tool to Improve Quality of Healthcare in Tanzania”. BMC Health Services Research 16.1 (2016): 578.

5. Hutchinson PL., et al. "Measuring client satisfaction and the quality of family planning services: a comparative analysis of 
public and private health facilities in Tanzania, Kenya and Ghana”. BMC Health Services Research 11.1 (2011): 203.

6. Lyu H., et al. "Patient satisfaction as a possible indicator of quality surgical care”. JAMA Surgery 148.4 (2013): 362-367.

7. Sack C., et al. "Is there an association between hospital accreditation and patient satisfaction with hospital care? A survey of 37000 patients treated by 73 hospitals". International Journal for Quality in Health Care 23.3 (2011): 278-283.

8. Ziaei H., et al. "Determinants of patient satisfaction with ophthalmic services". BMC Research Notes 4.1 (2011): 7.

9. McMullen M and Netland PA. "Wait time as a driver of overall patient satisfaction in an ophthalmology clinic". Clinical Ophthalmology 7 (2013): 1655.

10. King Khaled Eye Specialist Hospital". Vision and mission in 'About us' (2020).

11. Kingdom of Saudi Arabia. VISION 2030. A vibrant society with fulfilling lives of citizen and residents (2020): 22.

12. Mulisa T., et al. "Patients' satisfaction towards radiological service and associated factors in Hawassa University Teaching and referral hospital, Southern Ethiopia". BMC Health Services Research 17.1 (2017): 441.

13. Dean AG., et al. OpenEpi: Open Source Epidemiologic Statistics for Public Health, Version (2020).

14. Peterson KM., et al. "Patient satisfaction with care in an urban tertiary referral academic glaucoma clinic in the US". Patient Preference and Adherence 12 (2018): 775.

15. Ugwu AC., et al. "Patient satisfaction with obstetric ultrasonography”. Radiologic Technology 79.2 (2007): 113-118.

16. Sodani PR and Sharma K. "Assessing patient satisfaction for investigative services at public hospitals to improve quality of services". Journal of Natural Medicines 2 (2011): 404-408.

17. Karolczak-Kulesza M., et al. "Recommendations for ultrasound examination in ophthalmology. Part II: Orbital ultrasound". Journal of Ultrasonography 18.75 (2018): 349-354.

18. Nanda DR., et al. "Role of B-Scan Ultrasonography in Evaluating Posterior Segment of the Eye in the Event of Non Visualiza- tion of Fundus". Journal of Medical Science And Clinical Research 5.07 (2017): 25049-25055.

19. American Academy of Ophthalmology. Immersion A scan Ultrasound Biometry (2020).

20. Németh J., et al. "Color Doppler Ultrasound Examination in Orbital Diseases". In Neuro-Ophthalmology (2016): 247-252.

21. Vaz NF. "Patient satisfaction". In Healthcare Administration for Patient Safety and Engagement (2018): 186-200.

22. Mohamed EY., et al. "Patients' satisfaction with primary health care centers' services, Majmaah, Kingdom of Saudi of Saudi Arabia”. International Journal of Health Sciences 9.2 (2015): 163.

\section{Assets from publication with us}

- Prompt Acknowledgement after receiving the article

- Thorough Double blinded peer review

- Rapid Publication

- Issue of Publication Certificate

- High visibility of your Published work

Website: www.actascientific.com/

Submit Article: www.actascientific.com/submission.php

Email us: editor@actascientific.com

Contact us: +919182824667

Citation: Thafer S Bedaiwi., et al. "Patient Satisfaction with Regard to Ophthalmic Ultrasound Services Offered at King Khaled Eye Specialist Hospital, Riyadh City, Saudi Arabia: A Cross-Sectional Study". Acta Scientific Ophthalmology 4.5 (2021): 90-94. 